\title{
Anticipating the benefits of proposed information systems
}

Article in Journal of Information Technology · September 1995

DOI: $10.1057 /$ jit.1995.20

CITATIONS

28

2 authors, including:

Rajesh Mirani

University of Baltimore

28 PUBLICATIONS 550 CITATIONS

SEE PROFILE
READS

26

Some of the authors of this publication are also working on these related projects:

Project (To be Decided) View project

All content following this page was uploaded by Rajesh Mirani on 07 May 2015. 


\title{
Anticipating the benefits of proposed information systems
}

\author{
ALBERT L. LEDERER \\ Decision Sciences and Information Systems Area, School of Management, College of Business and Economics, \\ University of Kentucky, Lexington, KY 40506-0034, USA
}

\author{
RAJESH MIRANI \\ Information \& Quantitative Sciences, Merrick School of Business, University of Baltimore, 1420 N. Charles Street, \\ Baltimore, MD 21201, USA
}

\begin{abstract}
The assessment of the anticipated benefits of new information systems (IS) is important to IS planning. A study of the anticipated benefits of 178 projects as seen by IS managers and analysts revealed nine benefit factors. Business redesign emerged as the most important benefit. Some benefits are much more highly quantified than others. Organizations planned to spend more on projects whose top benefit was workforce reduction. Researchers can use these findings to study why and how organizations achieve the benefits of some proposals. Chief information officers can use them to help deliver new systems that better meet top management's expectations.
\end{abstract}

\section{Introduction}

Information systems planning has long been a critical issue to both chief information officers and senior business executives (Dickson et al., 1984; Moynihan, 1990; Neiderman et al., 1991). It includes the determination of the organization's key information needs and opportunities, the identification of broad initiatives to respond to those needs and opportunities, and the justification and prioritization of associated projects based on their anticipated costs and benefits (McLean and Soden, 1977; Willcocks, 1994).

Much has been written about the anticipated costs of information systems but less has appeared about their anticipated benefits. Nevertheless, an understanding of these anticipated benefits is very important for several reasons.

First, an understanding of the anticipated benefits of information systems can give researchers an opportunity to characterize IS projects thematically. For example, some information systems have been referred to as strategic information systems that enhance competitiveness (Ives and Learmonth, 1984; Runge and Earl, 1988; Clemons, 1991; Cash et al., 1992). However, evidence of the deliberate planning of such a type of system has not always been persuasive (Powell, 1992). In addition to strategic information systems, other information systems might be described in terms of their major benefits (Diromualdo, 1990).

Second, top management's personal experiences with information systems influences its attitude toward them (Feeny et al., 1992). Thus the anticipated benefits of a project can create top management's expectations for its outcome. After implementation, top management may informally compare the anticipated benefits to those delivered or it may employ a formal post-implementation audit. If the project was approved based on unattainable anticipated benefits, then the organization wastes scarce resources and top management's expectations will not be met. Conversely, if analysts failed to identify potentially realizable benefits of a project and thus it was not approved, its benefits will be lost; moreover, top management will be disappointed if it realizes the project was feasible.

Regardless of how top management assesses the project, the anticipated benefits offer it an opportunity to evaluate the project, IS management's ability to meet its commitments, and thus its credibility. This makes realistic benefits analysis critical to chief information officers.

Third, the accurate anticipation of benefits is a difficult task requiring considerable vision (Dos Santos, 1991). Critics have often claimed that the benefits of proposed information systems are not achieved (Loveman, 1988, 1991). By studying and understanding the anticipated benefits, analysts may be able to predict the achievable benefits better and thus realize them more often.

Finally, an understanding of the anticipated benefits that are currently attracting management support may guide information systems managers in proposing new projects and recommending their priorities. For example, some benefits may be more important than others and merit more attention (Diromualdo, 1990; 
Weill, 1992). Ideally, an information systems project can have quantifiable benefits (Bacon, 1992), thus quantitatively defined benefits may attract more funding than qualitative ones (or vice versa) and quantification be done more (or less) extensively (Rivard and Kaiser, 1989).

Hence research into the anticipated benefits of proposed information systems can be valuable. The study reported herein thus asked the following questions:

(1) What are the major, anticipated benefits of information systems projects?

(2) How important are the anticipated benefits relative to each other?

(3) Which anticipated benefits are quantified and which are not quantified?

(4) Which anticipated benefits are attracting top management support today?

\section{A framework for benefits analysis}

As part of the IS planning and implementation process, benefits analysis can be very political (Grover et al., 1988). Users, managers and IS professionals may have their own agendas. Nevertheless, the process can also be viewed as a rational process in order to answer the research questions in this paper.

Figure 1 shows where benefits analysis fits into the planning and implementation process. The organization analyses its environment and conceives computer initiatives to help it achieve its business objectives (Lederer and Gardiner, 1992). On that basis, information systems planners, top management, IS management, user departments or others may propose specific projects.

Cost and benefit analyses are conducted simultaneously based on information about the current project as well as previous ones (Bacon, 1992). While more technically-oriented information systems professionals might typically analyse costs, users and businessoriented information systems analysts assess benefits. Quantitative and non-quantitative benefits are both considered (Litecky, 1981; Keim and Janaro, 1982).

An evaluation of the benefits and costs follows. It considers not only financial criteria but also integrates management and development issues (Bacon, 1992). For example, it may incorporate the extent to which the proposed project meets explicit and implicit business objectives as well as how it responds to competitive systems and supports management decision making. It may also consider the project's probability of achieving the benefits as well as other criteria.

A decision to develop or cancel ensues. However, if the analysis initially reveals unexpectedly high costs, meagre

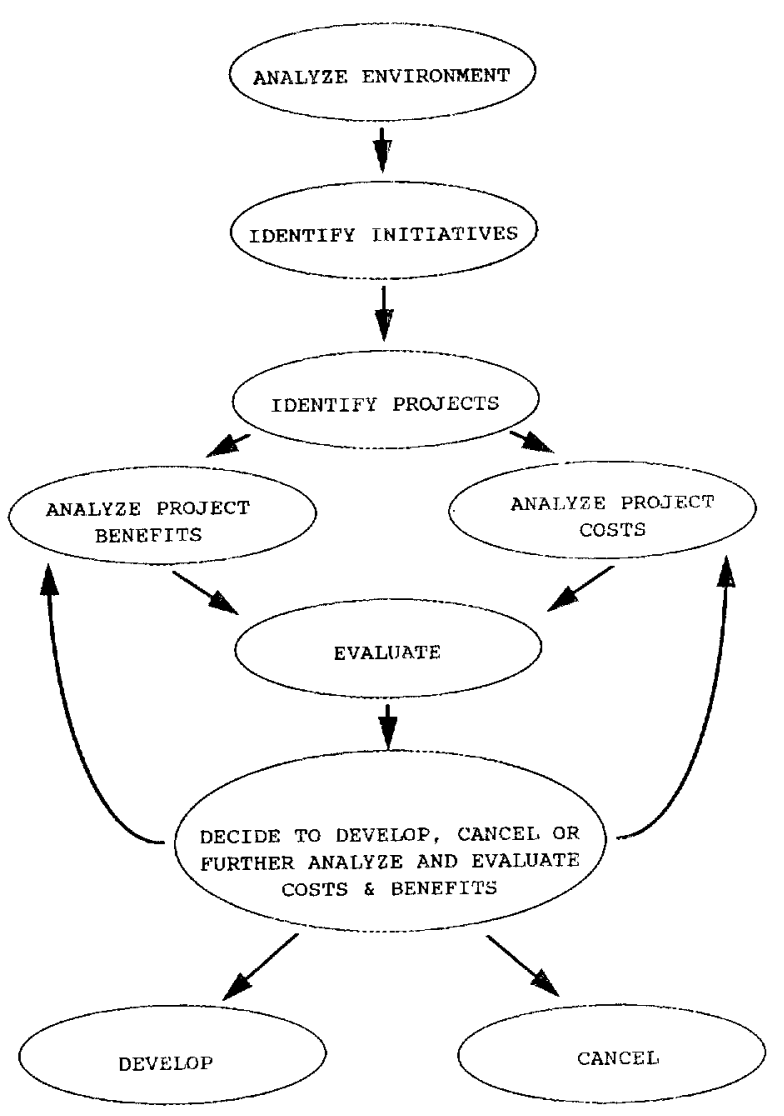

Figure 1 A framework for benefit analysis

benefits or other problems, it may require some reconsideration of the project, as shown by the back arrows in the figure. At this time, it may become evident that acceptable costs and benefits cannot be achieved and hence the project may be dropped without formally presenting it to a chief executive officer, vice president or other manager for final approval for development or cancellation.

\section{The potential anticipated benefits}

Observers have long attributed many benefits to information systems. Some are traditionally related to financial savings. For example, information systems have been used to control workforce costs by reducing the number of employees (Orli and Tom, 1987; Parker and Benson, 1987; Rivard and Kaiser, 1989; SullivanTrainor, 1989) or avoiding increases in them (Smith, 1983). Information systems have been used to reduce travel costs and communication costs (Smith, 1983). New information systems can also save money by reducing the number of modifications or enhancements to existing systems (Smith, 1983; Vaid-Raizada, 1983) 
and they can reduce costs by reducing hardware use (Orli and Tom, 1987).

Information systems provide benefits by increasing the usefulness of their output without necessarily providing financial impact. They enable faster retrieval or delivery of information (Rivard and Kaiser, 1989; SullivanTrainor, 1989) and present information in a more concise manner or better format (Rivard and Kaiser, 1989). They increase the flexibility of information requests (King and Schrems, 1978; Oril and Tom, 1987) and enable easier access to information (Orli and Tom, 1987; Rivard and Kaiser, 1989). They improve the accuracy of reliability of information (King and Schrems, 1978; Vaid-Raizada, 1983; Orli and Tom, 1987; Rivard and Kaiser, 1989) and increase the volume of information output (Rivard and Kaiser, 1989; Sullivan-Trainor, 1989).

The benefits of some information systems projects involve the facilitation of systems development. For example, new projects can allow other applications to be developed faster (Smith, 1983), permit previously unfeasible applications to be implemented (Oriol and Tom, 1987; Sullivan-Trainor, 1990) and provide greater data or software security (Vaid-Raizada, 1983).

Some benefits are related to management planning and control. New information systems can improve management information for strategic planning (King and Schrems, 1978; Parker and Benson, 1987), improve information for management control (King and Schrems, 1978; Orli and Tom, 1987; Parker and Benson, 1987) or improve information for operational control (Parker and Benson, 1987).

Other information systems improve productivity. They do this by speeding up transactions or shortening product cycles (Orli and Tom, 1987; Parker and Benson, 1987; Anonymous, 1990). They may enhance employee productivity or business efficiency (King and Schrems, 1978, Smith, 1983; McGugan, 1987; Rivard and Kaiser, 1989; Sullivan-Trainor, 1989, 1990). They also change the way the organization conducts business (Parker and Benson, 1987; Sullivan-Trainor, 1989).

Still other benefits are directly related to customers. These include improving customer relations (Orli and Tom, 1987; Rivard and Kaiser, 1989), providing new products or services to customers (Sullivan-Trainor, 1989) and providing better products or services to customers (Parker and Benson, 1987; Sullivan-Trainor, 1989; Anonymous, 1990).

Finally, some information systems improve the ability of the organization to compete. For example, they enhance competitiveness or create strategic advantage (Janulaitis, 1984; Lay, 1985; McGugan, 1987; Parker and Benson, 1987; Sullivan-Trainor, 1989, 1990; Anonymous, 1990). They enable the organization to catch up with competitors (Parker and Benson, 1987).
Other related benefits of the systems include that they align well with stated organizational goals (Parker and Benson, 1987), help establish useful linkages with other organizations (Parker and Benson, 1987) and enhance the credibility and prestige of the organization (Orli and Tom, 1987).

Table 1 contains a comprehensive list of these potential benefits. (A pilot test described below resulted in the addition of four items in Table 1.)

\section{Methodology}

The authors developed a questionnaire based on the framework and these benefits. Major parts were:

(1) A set of a few general questions about benefits analysis in the organization. Subjects were asked to answer in terms of what their organization defined as 'large projects' to prevent them from considering trivial tasks routinely handled without formal analysis.

(2) A set of questions about the analysis of the benefits of the most recent large project proposal for which benefits were estimated and an approval process was carried out resulting in either final approval or disapproval. Subjects identified the proposer, type of application, functional area of application, benefits analysts, approver and requested budget for the project.

(3) A list of anticipated benefits based on Table 1 . Respondents identified their view of the importance of each anticipated benefit relative to the other anticipated benefits of the most recently proposed project on a 1 to 7 scale ( 1 is not a benefit, 7 is very important) and the degree or extent to which the benefit, if anticipated for the project, was financially quantified on a 1 to 7 scale (where 1 is not quantified to all and 7 is fully quantified).

(4) Demographic questions about the organization and respondent.

Subjects were permitted to augment the responses to many of the questions. For example, they could add an anticipated benefit if it was not already identified in the questionnaire.

The authors conducted pilot tests with four experienced information systems managers and analysts. These resulted in the addition of four anticipated benefits, and other revisions to improve the questionnaire's clarity. The authors then mailed it to 936 randomly selected members of a large, North American association of information systems managers and ana- 
lysts. After a second mailing to non-respondents, a total of 200 responses were received. Since 33 were returned with incorrect addresses, the response rate was $22 \%$.

Because all of the respondents participated in or supervised the identification of benefits or the development of information systems based on them, they were knowledgeable about the questions in this study and are appropriate participants in it. However, it should be noted that their responses represent the perceptions of information systems managers and analysts and these could differ considerably from those of users and others.

\section{The sample}

Respondents were generally highly experienced and educated. They had worked in information systems for an average of 20 years with the past 12 at their current cmployer. Approximately 24 employees reported to each respondent with a range of $0-480$. As shown in Table 2, over $86 \%$ had a four-year degree and about half had attended at least some graduate school.

About one third of their firms were in manufacturing while insurance and government were the second and

Table 1 The benefits of IS

Save money by reducing the workforce

Save money by avoiding the need to increase the workforce

Save money by reducing travel costs

Save money by reducing communication costs

Save money by reducing system modification or enhancement costs

Save money by reducing hardware use

Increase return on financial assets

Enable faster retrieval or delivery of information or reports

Present information in a more concise manner or better format

Increase the flexibility of information requests

Enable easier access to information

Improve the accuracy or reliability of information

Increase the volume of information output

Allow other applications to be developed faster

Allow previously unfeasible applications to be implemented

Provide the ability to perform maintenance faster

Provide greater data or software security

Improve management information for strategic planning

Improve information for management control

Improve information for operational control

Speed-up transactions or shorten product cycles

Enhance employee productivity or business efficiency

Enable the organization to respond more quickly to change

Change the way the organization conducts business

Facilitate organizational adherence to governmental regulations

Improve customer relations

Provide new products or services to customers

Provide better products or services to customers

Enhance competitiveness or create strategic advantage

Enable the organization to catch up with competitors Align well with stated organizational goals Help establish useful linkages with other organizations Enhance the credibility and prestige of the organization.

Orli and 'Tom, 1987; Parker and Benson, 1987; Rivard and

Kaiser, 1989; Sullivan-Trainor, 1989

Smith, 1983

Smith, 1983

Smith, 1983

Smith, 1983; Vaid-Raizada, 1983

Orli and Tom, 1987

added during pilot

Rivard and Kaiser, 1989; Sullivan-Trainor, 1989

Rivard and Kaiser, 1989

King and Schrems, 1978; Orli and Tom, 1987

Orli and Tom, 1987; Rivard and Kaiser, 1989

King and Schrems, 1978; Vaid-Raizada, 1983; Orli and

Tom, 1987; Rivard and Kaiser, 1989

Rivard and Kaiser, 1989; Sullivan-Trainor, 1989

Smith, 1983

Orli and Tom, 1987; Sullivan-Trainor, 1990

added during pilot

Vaid-Raizada, 1983

King and Schrems, 1978; Parker and Benson, 1987

King and Schrems, 1978; Orli and Tom, 1987; Parker and Benson, 1987

Parker and Benson, 1987

Orli and Tom, 1987; Parker and Benson, 1987; Anonymous, 1990

King and Schrems, 1978; Smith, 1983; McGugan, 1987; Rivard and Kaiser, 1989; Sullivan-Trainor, 1989, 1990 added during pilot

Parker and Benson, 1987; Sullivan-Trainor, 1989

added during pilot

Orli and Tom, 1987; Rivard and Kaiser, 1989

Sullivan-Trainor, 1989

Parker and Benson, 1987; Sullivan-Trainor, 1989; Anonymous, 1990

Janulaitis, 1984; Lay, 1985; McGugan, 1987; Parker and Benson, 1987; Sullivan-Trainor, 1989, 1990; Anonymous, 1990

Parker and Benson, 1987

Parker and Benson, 1987

Parker and Benson, 1987

Orli and Tom, 1987 
Table 2 Demographics: respondents by education

\begin{tabular}{lrr}
\hline Education & Count & $\%$ \\
\hline Less than two-year college degree & 14 & 8 \\
Two-year college degree & 9 & 5 \\
Four-year college degree & 58 & 33 \\
Some graduate school & 30 & 17 \\
Masters & 60 & 34 \\
PhD & 3 & 2 \\
\hline
\end{tabular}

third most prominent employers (see Table 3). Their firms' IS departments had an average of 785 employees. Annual IS budgets averaged $\$ 52$ million with a range of $\$ 60000-\$ 2$ billion.

Of the 200 respondents, 190 answered a question as to whether or not their project was ultimately approved: 178 of their 190 projects, or $94 \%$, were approved. Thus only 12 progressed through the entire cost/benefit decision analysis without ultimately receiving management approval. This is consistent with the assertion above that clearly non-justifiable projects may be dropped from a decision analysis before a final decision. For the sake of homogeneity of data, the subsequent analysis uses these 178 projects.

Table 4 shows some characteristics of these projects, namely the proposer of the project, its application type, the functional areas affected by it, the participants in its benefits analysis and its final approver. Respondents could check more than one alternative for the proposer, application, functional area and participants questions. Hence the percentages in those portions of the table sum to more than $100 \%$. Their doing so suggests the collaborative nature of benefits analysis and the overlapping nature of IS project application types and functional areas.

Thus as the table shows, the most frequent proposers of the projects were user departments who suggested $61 \%$ of all projects; despite the current interest in planning, strategic planning groups proposed a much smaller percentage $(17 \%)$. The most common applications were transaction processing systems $(54 \%)$ and management information systems $(51 \%)$. Although the leading functional area was production $(33 \%)$, accounting $(24 \%)$ and finance $(22 \%)$ projects also had a share.

Table 3 Demographics: respondents by industry

\begin{tabular}{lcr}
\hline Industry & Count & $\%$ \\
\hline Banking & 8 & 4 \\
Education & 8 & 4 \\
Government & 18 & 10 \\
Health care & 12 & 7 \\
Insurance & 20 & 11 \\
Manufacturing & 58 & 33 \\
Utilities & 8 & 4 \\
Other & 46 & 26 \\
\hline
\end{tabular}

Management - both information systems $(81 \%)$ and user $(78 \%)$ - participated more frequently in the benefits analysis than did their subordinate user representatives and analyst/programmers. However, the chief executive officer was required to give final approval in nearly half $(45 \%)$ of the projects. Perhaps this was because the averge budget of the projects was $\$ 3.8$ million with a range of $\$ 4000-\$ 100000000$.

In any case, the projects in the sample represent a wide assortment. The sample represents a variety of industries and sizes. Moreover, no two subjects came from the

Table 4 Characteristics of projects

\begin{tabular}{lrr}
\hline & Number & $\%$ \\
\hline Proposers of Project & & \\
User department & 108 & 61 \\
Information systems department & 78 & 44 \\
Top management & 63 & 3 \\
Strategic planning group & 32 & 17 \\
Other individual employee & 4 & \\
Other & 11 & \\
Total & 296 &
\end{tabular}

Application of Project

Transaction processing system $\quad 96$

Management information system $\quad 90 \quad 51$

Decision support system

Office automation

Executive information system

Expert system

Other

Total

Functional Area of Project

Production

Accounting

Finance

Marketing

Human resources

Research and development

Other

Total

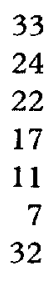

Participants in Benefits Analysis

IS department management

User management

User representatives

IS analyst/programmers

Other

Total

310

Final Approval of Project

Chief executive officer/president $\quad 73 \quad 45$

$\begin{array}{lll}\text { Steering committee } & 27 & 17\end{array}$

User vice president $\quad 16 \quad 9$

Financial vice president/controller $\quad 11 \quad 7$

$\begin{array}{lll}\text { Chief information officer } & 11 & 7\end{array}$

Other vice president $\quad 2 \quad 1$

Other 23

Totals 163 
same firm. Thus the results of the study probably generalize.

\section{Findings}

As expected, benefits analysis is important to IS managers and professionals. The mean rating of a general question on the importance of benefits analysis was 5.35 on a scale of $1-7$. This rating is significantly above a mid-point score of 4.00 (with $p \leqslant 0.001$ ) which would have indicated the respondents' indifference. On the other hand, the mean satisfaction rating of the subjects with their benefits analysis process was only 3.98 . Hence, it appears that benefits analysis is important but respondents are not particularly satisfied with it. This confirms the importance of studying benefits analysis. The specific questions and their answers now follow.

\section{What are the major anticipated benefits of IS projects?}

An exploratory factor analysis was conducted on the importance ratings to categorize benefits into thematically related groups. An exploratory, rather than confirmatory, analysis was used because no firm theoretical basis for a categorization exists. Thus, the loose grouping of benefits into the paragraphs of the literature review above is based on intuition rather than established theory.

The results of a principal components analysis followed by a varimax orthogonal rotation of the axes appear in Table 5. The analysis conducted on the 33 benefits yielded nine factors. If a benefit did not have a loading of 0.6 or more on at least one of the nine factors, it was dropped from subsequent analysis. Based on this criterion, 11 benefits were dropped. Together, the nine extracted factors accounted for $64.3 \%$ of the variance in the data. Reliability coefficients, as shown in Table 5, exceeded 0.60 for all factors with more than one item.

Table 5 Eigenvalue, percentage of variance and reliability for each factor

\begin{tabular}{llll}
\hline Factor & Eigenvalue & $\begin{array}{l}\text { Percentage } \\
\text { of variance }\end{array}$ & Reliability \\
\hline 1 & 8.55 & 25.9 & 0.86 \\
2 & 2.86 & 8.7 & 0.85 \\
3 & 2.34 & 7.1 & - \\
4 & 1.57 & 4.8 & 0.63 \\
5 & 1.29 & 3.9 & 0.63 \\
6 & 1.22 & 3.7 & - \\
7 & 1.16 & 3.5 & 0.70 \\
8 & 1.13 & 3.5 & - \\
9 & 1.06 & 3.2 & - \\
\hline
\end{tabular}

Table 6 The factors with items and loadings

\begin{tabular}{|c|c|}
\hline Factor & Loading \\
\hline \multicolumn{2}{|l|}{ Factor 1 : Improved information } \\
\hline \multicolumn{2}{|l|}{$\begin{array}{l}\text { Improve management information for strategic } \\
\text { planning }\end{array}$} \\
\hline \multicolumn{2}{|l|}{ Enable faster retrieval or delivery of information } \\
\hline Present information in a more concise manner & 0.730 \\
\hline Increase the flexibility of information requests & 0.699 \\
\hline Enable easier access to information & 0.783 \\
\hline $\begin{array}{l}\text { Improve the accuracy or reliability of } \\
\text { information }\end{array}$ & 0.641 \\
\hline Improve information for management control & 0.620 \\
\hline \multicolumn{2}{|l|}{ Factor 2: Strategic advantage } \\
\hline $\begin{array}{l}\text { Enhance competitiveness or create strategic } \\
\text { advantage }\end{array}$ & 0.614 \\
\hline Enhance the credibility and prestige of the & 0.736 \\
\hline Improve customer relations & 0.789 \\
\hline Provide new products or services to customers & 0.752 \\
\hline Provide betier products or services to customers & 0.798 \\
\hline Factor 3: Return on investment & 0.752 \\
\hline \multicolumn{2}{|l|}{ Factor 4: Reduced technology cost } \\
\hline $\begin{array}{l}\text { Save money by reducing system modification or } \\
\text { enhancement costs }\end{array}$ & 0.738 \\
\hline Save money by reducing hardware use & 0.621 \\
\hline \multicolumn{2}{|l|}{ Factor 5: Better applications development } \\
\hline $\begin{array}{l}\text { Allow previously unfeasible applications to be } \\
\text { implemented }\end{array}$ & 0.666 \\
\hline \multicolumn{2}{|l|}{ Factor 6: Reduced travel costs } \\
\hline \multicolumn{2}{|l|}{ Factor 7: Reduced workforce costs } \\
\hline $\begin{array}{l}\text { Save money by avoiding the need to increase the } \\
\text { workforce }\end{array}$ & 0.731 \\
\hline \multicolumn{2}{|l|}{ Factor $8:$ Business redesign } \\
\hline $\begin{array}{l}\text { Change the way the organization conducts } \\
\text { business }\end{array}$ & 0.753 \\
\hline Factor 9: Adherence to government regulations & \\
\hline governmental regulations & 0.681 \\
\hline
\end{tabular}

Table 6 shows the individual anticipated benefits and the factors on which they loaded. Meaningful names were assigned to each factor. Factor loadings appear for each benefit.

\section{How important are the anticipated benefits relative to each other?}

Table 7 shows the average importance rating for each factor. The mean for business redesign (F8) of 5.39 was significantly higher than the mean of all other import- 
Table 7 Most important factors by importance

\begin{tabular}{lll}
\hline Factor & $\begin{array}{l}\text { Mean importance } \\
\text { rating }\end{array}$ & $\begin{array}{l}\text { Projects rated } \\
\text { most important }\end{array}$ \\
\hline F8 Business redesign & 5.39 & 98 \\
F1 Improved information & 4.70 & 29 \\
F2 Strategic advantage & 4.00 & 17 \\
F7 Reduced workforce costs & 3.47 & 20 \\
F4 Reduced technology cost & 3.11 & 16 \\
F3 Return on investment & 3.03 & 27 \\
F5 Better applications development & 2.98 & 15 \\
F9 Adherence to government regulations & 2.75 & 35 \\
F6 Reduced travel costs & 1.46 & 3 \\
\hline
\end{tabular}

ance ratings in the table $(p \leqslant 0.001)$. The mean for improved information (F1) of 4.70 was significantly higher than the mean of all other importance ratings below it in the table $(p \leqslant 0.001)$. The mean for strategic advantage (F2) of 4.00 was significantly higher than the mean of all other importance ratings below it in the table $(p \leqslant 0.01)$.

The table also shows the number of projects where each factor was most important. The total number of projects exceeds 178 because more than one factor tied for the highest rating in several projects.

\section{Which anticipated benefits are quantified and which are not quantified?}

Table 8 shows the average rating of the extent to which each anticipated benefit was quantified. These figures include only the most important benefit in each project. The use of the most important benefit eliminated the consideration of unimportant benefits which analysts might choose not to quantify in order to save the time and effort required to do so. The table also shows the level of statistical significance for the ratings exceeding a mid-point score of 4.00 , the expected mean if all ratings were assigned randomly. The sequence in the table of quantification ratings for adherence to government regulations, reduced workforce costs and business redesign does not correspond with the sequence by statistical significance due to different sample sizes for each factor.

Table 8 Most important factors by quantification

\begin{tabular}{lll}
\hline Factor & Quantification & $p \leqslant$ \\
\hline F3 Return on investment & 5.56 & 0.01 \\
F6 Reduced travel costs & 5.50 & $\mathrm{~ns}$ \\
F2 Strategic advantage & 5.47 & 0.01 \\
F4 Reduced technology cost & 5.32 & 0.01 \\
F7 Reduced workforce costs & 4.94 & 0.10 \\
F9 Adherence to government regulations & 4.91 & 0.05 \\
F8 Business redesign & 4.88 & 0.01 \\
F5 Better applications development & 4.18 & $\mathrm{~ns}$ \\
F1 Improved information & 4.08 & $\mathrm{~ns}$ \\
\hline
\end{tabular}

\section{Which anticipated benefits are attracting top management support today?}

Table 9 shows the average budget for each project. They are categorized by the most important factor for the project.

\section{Discussion}

The findings provide a basis for discussing the four research questions.

\section{The major anticipated benefits}

Factor analysis produced a set of meaningful factors. Five of them have multiple items. Improved information (factor 1) deals with very broad benefits that focus on individual users and their ability to have better retrieval, conciseness, flexibility, ease of access, accuracy and reliability in their data. It is not surprising that organizations plan new information systems distinguished by these benefits. After all, these items have long been considered among the major benefits of information systems and are a major objective in developing them (Rivard and Kaiser, 1989).

On the other hand, strategic advantage (factor 2) is a relatively newer benefit. Its items focus on organizational issues rather than the individual user concerns. They involve competitors, customers, products and services and these are the typically discussed aspects of strategic

Table 9 Most important factors by project budget

\begin{tabular}{ll}
\hline Factor & Project budget \\
\hline F7 Reduced workforce costs & 8043000 \\
F9 Adherence to government regulations & 4236000 \\
F8 Business redesign & 4082000 \\
F2 Strategic advantage & 3104000 \\
F3 Return on investment & 2855000 \\
F6 Reduced travel costs & 1828000 \\
F5 Better applications development & 1287000 \\
F1 Improved information & 876000 \\
F4 Reduced technology cost & 552000 \\
\hline
\end{tabular}


information systems. In a sense, factor analysis validates the existence of a strategic advantage type of benefit. In doing so, it confirms a greater interest in competitive applications than had previously appeared (Willcocks and Lester, 1991). More importantly, it confirms the notion that organizations deliberately use planning to identify new information systems that will deliver strategic advantage (Earl, 1993).

Three factors had two items. Reduced technology cost (factor 4 ) is probably a less frequently discussed benefit of new information systems. However, one of its two items, saving money by reducing hardware use, is associated with the current trend toward downsizing from more expensive mainframes to local area networks of personal computers. It is thus a meaningful factor.

Better applications development (factor 5) focuses on issues related to IS professionals and their responsibilities in developing new applications. Perhaps the only out-of-place item in the entire set of factors is saving money by reducing system modification or enhancement costs; it appeared in reduced technology cost (factor 4) but might have been expected to appear within better applications development (factor 5). Nevertheless, an argument could easily be made for it in either factor.

Reduced workforce costs (factor 7), the last multiple item factor, focuses reasonably on labour cost reduction and labour cost avoidance. It thus substantiates the older, conventional view of the computer as a laboursaving device for reducing costs and improving operational efficiency (Diromualdo, 1990).

Four factors had one item. Return on investment (factor 3 ) is a very tangible benefit. Reduced travel costs (factor 6) may not be so popular but it is certainly a benefit of group decision support and other telecommunications-based systems. Adherence to government regulations (factor 9) often imposes inefficiencies on manual processes and thus demands that many new information systems be built.

Business redesign (factor 8 ), the final one-item factor, refers to a tool that uses information technology to enhance boundary-crossing, customer-driven processes and that is quickly growing popular (Davenport and Short, 1990). It is being highly praised for its ability to improve business performance dramatically by reducing cost and time and by increasing quality (Davenport, 1993).

Hence, the factor structure gives a meaningful perspective on the anticipated benefits of information systems.

\section{Relative importance of anticipated benefits}

All anticipated benefits are not equally important. It is apparent from Table 7 that business redesign has emerged as a very important anticipated benefit of information systems. Of the respondents, $55 \%$ identified it as the top benefit (or tied for top) of their project and its rating of 5.93 was the highest across all 178 projects. Clearly, respondents now perceive that they use information technology as a means to 'change the way the organization conducts business' (the exact quote of the single item in the factor).

Improved information had the second highest importance rating. Its rating may be unusual but only because the benefit is very general and usually thought of as highly intangible. On the other hand, strategic advantage, with the third highest rating, apparently is now taken fairly seriously by management in the justification process.

The relatively low rating of better applications development is interesting because applications with this benefit typically affect the information systems department. Apparently, projects benefiting the department are not seen as especially important (even by the information systems respondents in this study!).

By having the second lowest average rating, adherence to government regulations appears as not a very important anticipated benefit also. On the other hand, since it has the second highest number of projects as the top benefit, it is quite important. This implies that when adherence is important, it is very important because the organization must meet government requirements.

Reduced travel costs was the most important in only three projects. Its importance rating was lowest. Hence it should probably be disregarded.

\section{Quantified and non-quantified anticipated benefits}

Table 8 shows that the most important benefits typically are all quantified to some extent for at least some projects. This is evident because on the 1-7 scale, all averages were above a mid-point of 4.00 . It means that benefits analysts understand the value of quantification and try to quantify the basis for their justification.

Nevertheless, it may be possible to use the table to classify benefits in terms of their degree of quantification. Because the means of return on investment, strategic advantage, reduced technology cost and business redesign are significantly above an expected indifference value of 4.00 , one might say that they are highly quantified benefits. Because reduced workforce costs and adherence to government regulations are well above 4.00 but not significantly so at the same level of confidence, one might describe them simply as well quantified. Finally, because better applications development and improved information are so close to 4.00 , they might be described as less quantified. As reduced travel costs was the top benefit in so few projects, this classification ignores it. 
In addition to offering a classification scheme for benefits quantification, the table may offer more insights into anticipated benefits. Thus, while it may not be particularly surprising that return on investment is so highly quantitative, it may surprise some observers that benefits analysts quantify strategic advantage benefits so highly. In earlier days, strategic applications were thought to be less predictable. Apparently analysts now feel they can and should quantify these benefits or at least discuss projects in terms of them.

Likewise, one might expect improved information to be more quantified because it is such an important benefit (as seen in Table 7). Perhaps, however, it is the least quantified benefit simply because it is so general; indeed, being general may make it difficult to quantify.

It is also surprising that better applications development is not quantified more. Because this benefit typically affects information systems professionals directly and because they are experienced in the assessment of the benefits of information systems, one might expect more quantification. On the other hand, perhaps they are less able to envision such quantitative benefits affecting their own department or are reluctant to commit to them by quantifying them.

\section{Benefits attracting top management support}

As Table 9 reveals, organizations spend a substantial amount of money on projects aimed at reduced workforce costs. Although subjects did not see this benefit as particularly important, their organizations invest generously in them. Perhaps equally interesting is that much less is spent on better applications development - despite its relevance to the IS department; and on improved information projects - despite its importance.

\section{Contributions to research}

This research has identified a set of nine factors categorizing the anticipated benefits of proposed information systems. No previous research has used empirical data to produce such a scheme. The scheme is valuable because it can be used as a measurement tool to increase the understanding of both proposed and implemented information systems among researchers concerned about information systems planning. Moreover, the emergence of meaningful themes in this research gives impetus to the study of the analysis process that identifies them.

The set of factors can thus help researchers investigate why the benefits of information systems are or are not achieved. Researchers can use it to identify both the anticipated benefits of particular proposed systems and later their final, delivered benefits. Researchers would then use pre- and post-implementation tracking to investigate why some benefits may have been achieved while others were not. In other words, used in further research, it may help focus on benefits identification and implementation practices that result in the more successful achievement of benefits than do other practices.

Researchers might thus ask: what are the key issues in the successful identification of realizable benefits? How can benefits be identified more accurately? How are benefits quantified and how should they be quantified? How does management evaluate the anticipated benefits presented to them and how does it decide to support a project? Most relevant to the study at hand, do the answers to such questions differ depending on the types of benefits sought from the proposed system?

Researchers might ask these questions by presenting the factors in this study to information systems professionals as done herein. In addition, they might also use them by presenting them to managers or users and thus gain other perspectives on the issues. It is conceivable that information systems professionals have quite different views on the benefits of information systems than do managers and users. In either case, researchers would make an important contribution by helping managers better predict and achieve the planned benefits of new information systems.

Finally, the finding that business redesign is seen as such an important benefit suggests that researchers focus more attention on it. Because successful business redesign is so heavily contingent upon organizational issues, researchers should step up their study of the politics of information (Davenport et al., 1992).

\section{Contributions to practice}

This research makes several contributions to practitioners involved in information systems planning. For example, although earlier authors have described each of the potential benefits, Table 1 can serve as a contemporary checklist to planners of possible benefits and they can use it as such when initially preparing benefits analyses.

The nine anticipated benefits themes, represented by the factors, can also be useful to practitioners. Specifically, chief information officers and other information systems managers can use them to organize, describe, summarize and communicate the benefits of new and existing information systems to other managers and thus educate them about their plans and accomplishments.

Information systems planners can also use the factors to assess their current portfolio of existing applications. They can assess the portfolio to help decide whether the mix of applications in the portfolio is consistent with the overall corporate role of information systems. For example, if most of their applications provide improved information yet their corporate goals aim at creating a 
strategic advantage or reduced workforce, then they may want to consider other applications with, say, strategic advantage or reduced workforce benefits.

Information systems managers can also use the factors to evaluate their information systems by comparing current ratings with desired ratings of specific projects or functional areas. They could rate the projects themselves or seek the input of other information systems professionals, users or managers. This could help them find opportunities for the improvement of existing systems or the development of new ones.

In addition to the individual items and factors, the findings with regard to importance, quantification and budget offer meaningful information for practitioners. For example, this research demonstrates clearly that management invests in workforce reduction. Not nearly as much was spent on other benefits despite their importance; improved information is the most notable example of an important benefit with little spent on it. In attempting to justify large-scale projects, perhaps information systems planners should more seriously assess reduced workforce benefits.

Likewise, this study suggests that all important benefits are quantified to at least some extent in at least some projects. Apparently, despite the growing emphasis on quality in business and industry today (Juran, 1989), many top managers still regard the quantification of benefits seriously. Despite the difficulty involved in quantifying them, even strategic advantage and business redesign benefits are highly quantified. This suggests that while emphasizing quality in justification studies, planners should not disregard quantification.

As a final example, the very substantial importance of the business redesign benefit suggests that many organizations now take it very seriously. Presumably IS managers and analysts feel that top management takes the benefit seriously. Organizations that have not begun identifying and expressing benefits in these terms should probably consider doing so now. Organizations that have begun redesigning their business processes should be sure they fully understand this exciting new approach.

\section{References}

Anonymous (1990) Evaluating technology's payback. IBM Directions, 4(3), 29-31.

Bacon, C.J. (1992) The use of decision criterion in selecting information systems/technology investments. MIS Quarterly, 16(3), 335-54.

Cash, J.I., McFarlan, F.W., McKinney, J.L. and Applegate, L.M. (1992) Corporate Information Systems Management: Text and Cases (Richard D. Irwin, Homewood, IL).

Clemons, E. (1991) Evaluation of strategic investment in information technology. Communications of the $A C M$, 34(1), 22-36.
Davenport, T.H. (1993) Process Innovation: Reengineering Work through Information Technology (Harvard Business School Press, Boston).

Davenport, T.H., Eccles, R.G. and Prusak, L. (1992) Information politics. Sloan Management Review, 34(1), 53-65.

Davenport, T.H. and Short, J.E. (1990) The new industrial engineering: information technology and business process redesign. Sloan Management Review, 31(4), 11-27.

Dickson, G.W., I.eitheiser, R.I., Wetherbe, J.C. and Nechis, M. (1984) Key information systems issues in the 1980 s. MIS Quarterly, 10(3), 135-59.

Diromualdo, A.P. (1990) Toward asset-based IT. CIO, December, 18-19.

Dos Santos, B. (1991) Justifying investments in new information technolngies. Foumal of Management Information Systems, 7(4), $71-90$.

Earl, M.J. (1993) Experiences in strategic information systems planning. MIS Quarterly, 17(1), 1-20.

Feeny, D.F., Edwards, B.R. and Simpson, K.M. (1992) Understanding the CEO/CIO relationship, MIS Quarterly, 16(4), 435-48.

Grover, V., Lederer, A.L. and Sabherwal, R. (1988) Recognizing the politics of MIS. Irformation and Management, 14, 145-56.

Ives, B. and Learmonth, $G$. (1984) The information system as a competitive weapon. Communications of the $A C M$, 27(12), 1193-201.

Janulaitis, V.M. (1984) Are the risks worth taking? Computerworld, 18(33), August 13, 13-22.

Juran, J.M. (1989) Furan on Leadership for Quaity (The Free Press, NY).

Keim, R.T. and Janaro, R. (1982) Cost/benefit analysis of MIS. Foumal of Systems Management, 33(9), 20-5.

King, J.L. and Schrems, E.L. (1978) Cost-benefit analysis in information systems development and operation. Computing Surveys, 10(1), 19-34.

Lay, P.M.W. (1985) Beware of the cost/benefit model for IS project evaluation. Foumal of Systems Management, 36(6), $30-5$.

Lederer, A.L. and Gardiner, V. (1992) 'The process of strategic information planning. Youmal of Strategic Information Systems, 1(2), 76-83.

I.itecky, C.R. (1981) Intangibles in cost/benefit analysis. foumal of Systems Management, 32(2), February, 15-17.

Loveman, G. (1988) An assessment of the productivity impact of information technologies, working paper 88-054, Massachusetts Institute of Technology/Sloan School of Management, Cambridge, MA.

Loveman, G. (1991) Cash drain, no gain. Computerworld, November 25, 69-72.

McGugan, I, (1987) Competitive advantages vs. tyrannosaurs techie. Computing Canada, 13(9), April 30, 18, 20.

McLean, E.R. and Soden, J.V. (1977) Strategic Planning for MIS (Wiley and Sons, NY).

Moynihan, 'Г. (1990) What chief executives and senior managers want from their IT departments. MIS Quarterly 14(1), 15-26.

Neiderman, F., Brancheau, J.C. and Wetherbe, J.C. (1991) Information systems management issues for the 1990s. MIS Quarterly, 15(4), 475-500. 
Orli, R.J. and Tom, J.C. (1987) If it's worth more than it costs, buy it! Foumal of Information Systems Management, 4(3), 85. 9.

Parker, M.M. and Benson, R.J. (1987) Information economics: an introduction. Datamation, 33(23), 86-96.

Powell, P. (1992) Information technology and business strategy: a synthesis of the case for reverse causality, in Proceedings of the Thirteenth International Conference on Information Systems, 13-16 December, Dallas, Texas, pp. 71-80.

Rivard, E. and Kaiser, K. (1989) The benefit of quality IS. Datamation, 35(2), 53-8.

Runge, D. and Earl, M. (1988) Gaining competitive advantage from telecommunications, in Information Management: The Strategic Dimension, Earl M. (ed) (Oxford University Press, Oxford).

Smith, R.D. (1983) Measuring the intangible benefits of computer-based information systems. Fournal of Systems Management, 33(9), 22-7.

Sullivan-Trainor, M.L. (1989) The push for proof of information systems payoff. Computerworld, 23(14), 55-61.

Sullivan-Trainor, M.L. (1990) End of IS budgets as we know them? Computerworld, 24(52,53), 15.

Vaid-Raizada, V.K. (1983) Incorporation of intangibles in computer selection decisions. Foumal of Systems Management, 33(11), 30-6.

Weill, P. (1992) The relationship between investment in information technology and firm performance: a study of the valve manufacturing sector. Information Systems Research, 3(4), 307-33.

Willcocks, 1. (1994) Information Management: The Evaluation of Information Systems Investment (Chapman and Hall, London).

Willcocks, L. and Lester, S. (1991) Information systems investments: evaluation at the feasibility stage of projects. Technovation, 11(5), 283-302.

\section{Biographical notes}

Albert L. Lederer is Professor of MIS and Ashland Oil Research Fellow in the College of Business and Economics at the University of Kentucky. His articles have appeared previously in the foumal of Information Technology, MIS Quarterly, Communications of the ACM, fournal of MIS, Information Systems Research, Decision Sciences, Sloan Management Review and elsewhere. He is senior editor of the fournal of Information Technology Management. He holds a PhD in Industrial and Systems Engineering from the Ohio State University, an MSc in Computer and Information Sciences from Ohio State, and a BA in Psychology from the University of Cincinnati.

Rajesh Mirani is Assistant Professor in the Information and Quantitative Sciences Department of the Merrick School of Business at the University of Baltimore. His articles have appeared or are forthcoming in the MIS Quarterly, fournal of MIS, Decision Sciences and other periodicals. He earned his $\mathrm{PhD}$ in MIS from the Katz Graduate School of Business at the University of Pittsburgh, his BTech from the Indian Institute of Technology, Kharagpur, and his MBA from the Indian Institute of Management in Calcutta.

Address for correspondence: Albert Lederer, 425C Business and Economics Building, Decision Sciences and Information Systems Area, School of Management, College of Business and Economics, University of Kentucky, Lexington, KY 40506-0034, USA. E-mail: lederer@ukcc.uky.edu 